\title{
HER2/neu Status in Breast Cancer Specimens: Comparison of Immunohistochemistry (IHC) and Fluorescence in situ Hybridization (FISH) Methods
}

\author{
Estado del HER2/neu en Especímenes con Cáncer de Mama: Comparación entre los \\ Métodos de Inmunohistoquímica (IHC) y Fluorescencia de Hibridación In Situ (FISH)
}

Yesim Saglıcan* \& Ümit Ince*

SAGLICAN, Y. \& INCE, Ü. HER2/neu status in breast cancer specimens: Comparison of immunohistochemistry (IHC) and fluorescence in situ hybridization (FISH) methods. Int. J. Morphol., 33(2):737-742, 2015.

SUMMARY: HER2 amplification or overexpression is considered as disease outcome and a predictive marker of response to treatment in breast cancer. The present study aimed to compare the results of IHC and FISH for determining HER2 and to search the interpretational differences. Samples $(n=169)$, of which 31 were the paraffin blocks sent from outer centers, that underwent FISH analysis for HER-2 were included. Samples were re-reviewed by IHC in our laboratory. FISH test was negative in 131 (77.5\%) and positive in $38(22.5 \%)$. When those with previous IHC $0-1+$ were re-reviewed, the results were found again $0-1+$ and none of them was FISH positive. Inconsistency between re-reviewed IHC and previous IHC results was $25 \%$ for those with $2+$ score and $11 \%$ for those with $3+$ score. Consistency between IHC and FISH was $17 \%$ and $67 \%$ for previous IHC $2+$ and $3+$, respectively, whereas it was $23 \%$ and $\% 75$ for re-reviewed IHC $2+$ and $3+$, respectively. Whilst $79 \%$ of the samples evaluated as $2+$ by the inexperienced pathologist were found to be $0-1+$ on the re-review, all of them were FISH negative. According to our results, we suggest that samples with IHC $2+$ should be re-reviewed by consulting with an experienced pathologist.

KEY WORDS: Breast cancer; HER2; Immunocytochemistry; FISH technique.

\section{INTRODUCTION}

Human epidermal growth factor receptor protein-2 (HER2/neu; c-erb-2) gene is located on human chromosome 17 and encodes the HER2 protein. HER2 overexpression is observed in about 15\%-20\% of breast cancer patients (Jacot et al., 2013; Mukai, 2010; Ross, 20099). HER2 amplification or overexpression is considered as disease outcome and as the predictive marker of response to treatment (Jacot et al.; Bravatà et al., 2013). HER2-positive tumors are usually resistant to cytoxan- or tamoxifen-based regimens, but sensitive to anthracycline-based chemotherapy and trastuzumab therapy. The trastuzumab antibody binds to the extracellular domain of HER2, which is a transmembrane tyrosine kinase receptor, and then growth inhibition and apoptosis of tumor cells overexpressing HER2 occur (Bravatà et al.). Trastuzumab has made substantial contributions to the adjuvant treatment of HER2-positive breast cancers. Studies carried out with second generation drugs are ongoing (Jelovac \& Wolff, 2012). With the advent of therapy to target the HER2/neu protein, it has become a requested marker to identify patients appropriate for chemotherapy with the anti-HER 2 monoclonal antibody trastuzumab.

Various commercially available kits or in-house protocols are used to determine HER2 status and comparison studies have been conducted (Cayre et al., 2007; Manion et al., 2011; O'Grady et al., 2010). For the determination of HER2/neu protein expression, immunohistochemistry (IHC) is an exclusively used method and almost a standard part of pathology reports in invasive breast cancer. In cases of equivocal (2+) IHC results or without previous IHC, FISH techniques are used for detecting HER2 gene amplification. Fluorescence in situ hybridization (FISH) has been reported to be a method of choice to detect the candidates for HER2targeted therapy in terms of accuracy, reproducibility, and predictivity (Sauter et al., 2009). Ellis et al. (2005) reported that the use of IHC and FISH methods in combination was the most effective strategy even though it was not cost 
effective. The aim of the present study was to compare the results of IHC and FISH in our laboratory and to search the interpretational differences.

\section{MATERIAL AND METHOD}

All patients with invasive breast cancer, who underwent FISH analysis for HER-2 between 2009 and 2012 in our department, were included in the study. Of 169 samples included in the study, 31 were the paraffin blocks sent from outer centers for FISH analysis.

Immunohistochemistry. Immunohistochemical staining for HER2/neu was performed on $4 \mu \mathrm{m}$ sections of formalinfixed, paraffin-embedded tissues. Sections were stained using Ventana HER2 kit (Pathway Anti-Her2/neu (4B5), Ventana Medical Systems Inc., Tucson, Arizona USA) following the manufacturer's guidelines. The same tissue blocks were used for both IHC and FISH.

Fluorescence in situ hybridization. Following the preparatory steps and pretreatment, denaturation and hybridization was performed on day 1. ZytoLight $₫$ SPEC HER2 /CEN17 dual color probe kit (Zytovision Molecular Diagnostics Simplified, Bremerhaven Germany) was used for hybridization. The slides were hybridized overnight at $37{ }^{\circ} \mathrm{C}$. On day 2, following the washing steps, DAPI/ Antifade-solution (MT1) solution was dropped onto the slides. Evaluation of the slides was carried out by Olympus BX51 fluorescent microscope. With the use of appropriate filters, the signals of labeled HER2 gene (green) and alphasatellite-sequences of the centromere of chromosome 17 (red) were counted on 100 cells for each sample.

Interpretation of the IHC slides that was previously evaluated by different pathologists in our department, were re-reviewed by two pathologists with 25 years of experience in breast pathology and blind to the first results. Consensus of these two pathologists was considered as a final decision. The results of experienced pathologists were assigned to Group A, the results of other pathologists were assigned to Group B, and the results of the tissues sent from outer centers were assigned to Group C. FISH evaluation and scoring was performed by the same experienced pathologists.

For the evaluation of HER-2 overexpression by IHC and FISH, the United States Food and Drug Administration (FDA) and the American Society of Clinical Oncology/ College of American Pathologists (ASCO/CAP) guidelines were used (Wolff et al., 2013).

\section{RESULTS}

In the present study, samples from 169 patients with invasive breast cancer, who underwent FISH analysis for HER2/neu, were re-evaluated. The mean score of samples that underwent FISH analysis was 1.93 (ranged between 0.4 and 15.0). The results were negative in 131 samples (77.5\%) and positive in 38 samples (22.5\%). HER $2 /$ neu IHC results were available for 138 samples. All results are summarized in Table I.

Table I. HER2/neu FISH and IHC results.

\begin{tabular}{llc}
\hline & HER2/neu & $\mathbf{n}(\mathbf{\%})$ \\
\hline FISH (n=1 69) & Negative & $131(77.5)$ \\
& Positive & $38(22.5)$ \\
IHC $(\mathbf{n}=\mathbf{1 3 8})$ & 0: Negative & $8(5.8)$ \\
& 1+: Negative & $6(4.2)$ \\
& 2+: Equivocal & $115(83.3)$ \\
& 3+: Positive & $9(6.5)$ \\
\hline
\end{tabular}

Of the samples with HER2/neu IHC results of $0-1+$, $100 \%$ were FISH negative. Of the samples with IHC $2+$ and IHC $3+, 17.4 \%$ and $66.7 \%$ were FISH positive, respectively (Table II).

Table II. Comparison of the results of HER2/neu IHC and FISH analyses $(n=138)$.

\begin{tabular}{lcc}
\hline & FISH (-) & FISH (+) \\
\cline { 2 - 3 } IHC & n (\%) & n (\%) \\
\hline $0-1+$ & $\mathbf{1 4 ( 1 0 0 . 0 )}$ & $0(0.0)$ \\
$2+$ & $95(82.6)$ & $\mathbf{2 0 ( 1 7 . 4 )}$ \\
$3+$ & $3(33.3)$ & $\mathbf{6}(\mathbf{6 6 . 7 )}$ \\
\hline
\end{tabular}

Comparison of the IHC results evaluated by experienced pathologist and inexperienced pathologist is demonstrated in Table III. Comparison of the IHC results evaluated by experienced pathologist and FISH results is presented in Table IV. Of the samples with IHC $0-1+$, which was evaluated by experienced pathologist, $100 \%$ were FISH negative. However, of the samples with IHC 2+ and 3+, $23.3 \%$ and $75 \%$ were FISH positive, respectively.

Table III. IHC results evaluated by experienced pathologist and inexperienced pathologist $(n=138)$.

\begin{tabular}{lccc}
\hline \multirow{2}{*}{ Previous IHC } & \multicolumn{3}{c}{ Re-reviewed IHC } \\
& $\mathbf{0 - 1 +}$ & $\mathbf{2 +}$ & $\mathbf{3}+$ \\
\cline { 2 - 4 } & $\mathbf{n ( \% )}$ & $\mathbf{n}(\%)$ & $\mathbf{n ( \% )}$ \\
\hline$-1+$ & $\mathbf{1 4 ( 1 0 0 . 0 )}$ & $0(0.0)$ & $0(0.0)$ \\
$2+$ & $29(25.2)$ & $\mathbf{8 6}(\mathbf{7 4 . 8})$ & $0(0.0)$ \\
$3+$ & $1(11.1)$ & $0(0.0)$ & $\mathbf{8 ( 8 8 . 9}$ \\
\hline
\end{tabular}


Table IV. Re-reviewed HER2/neu IHC and FISH results $(\mathrm{n}=138)$

\begin{tabular}{lcc}
\hline & & \\
\cline { 2 - 3 } Re-reviewed IHC & $\mathbf{n}(\%)$ & n (\%) \\
\hline $0-1+$ & $\mathbf{4 4 ( 1 0 0 . 0 )}$ & $0(0.0)$ \\
$2+$ & $66(76.7)$ & $\mathbf{2 0}(\mathbf{2 3 . 3 )}$ \\
$3+$ & $2(25.0)$ & $\mathbf{6 ( 7 5 . 0 )}$ \\
\hline
\end{tabular}

Comparison of previous IHC results with the final evaluation and interpretation differences of pathologists are presented in Table V; re-reviewed IHC results of the blocks from outer centers are also presented. When the samples that were $2+$ in the previous HER2/neu IHC analysis were rereviewed, $82.1 \%$ of those in Group A, $21.4 \%$ of those in Group $\mathrm{B}$, and all of those in Group $\mathrm{C}$ were found to be $2+$ again.

\section{DISCUSSION}

IHC method for testing HER-2/neu expression is a standard procedure in our laboratory and a part of our pathology reports in invasive breast carcinomas. FISH is the subsequent and gold method in equivocal (2+) IHC cases.

It is controversial which method is the best for HER2/ neu determination. Available methods evaluate HER/neu through different aspects. Whilst IHC method evaluates protein overexpression on cell surface in tissue samples, FISH method determines the number of copies of the gene that codes this protein. Enzyme linked immunosorbent assay (ELISA) method measures serum antigen levels (Yeh, 2002). In the present study, IHC and FISH methods were performed using FDA-approved kits and the results were compared.
Table V. Comparison of previous and re-reviewed IHC results.

\begin{tabular}{|c|c|c|c|c|}
\hline \multirow[b]{3}{*}{ Pathologist } & \multirow[b]{3}{*}{ Previous IHC } & \multicolumn{3}{|c|}{ Re-reviewed IHC } \\
\hline & & $0-1+$ & $2+$ & $3+$ \\
\hline & & n (\%) & n (\%) & n (\%) \\
\hline \multirow[t]{3}{*}{$\mathbf{A}$} & $0-1+$ & $14(100.0)$ & $0(0.0)$ & $0(0.0)$ \\
\hline & $2+$ & $14(17.9)$ & $64(82.1)$ & $0(0.0)$ \\
\hline & $3+$ & $0(0.0)$ & $0(0.0)$ & $8(100.0$ \\
\hline \multirow[t]{2}{*}{ B } & $2+$ & $15(78.9)$ & $4(21.4)$ & $0(0.0)$ \\
\hline & $3+$ & $1(100.0)$ & $0(0.0)$ & $0(0.0)$ \\
\hline $\mathbf{C}$ & $2+$ & $0(0.0)$ & $18(100.0)$ & $0(0.0)$ \\
\hline
\end{tabular}

$\mathrm{A}=$ Experienced pathologist; $\mathrm{B}=$ Inexperienced pathologist; $\mathrm{C}=$ Tissues from outer centers.
Being rapid and technically easier and cheaper are the main advantages of IHC; however, evaluation is subjective and shows interobserver variability. Moreover, pre-analytic and analytic processes influence immunoreactivity. FISH gives quantitative results with lower interobserver variability. Nevertheless, FISH is a more time-consuming method, is difficult to apply, and requires trained technician. It is more expensive since it requires test kits and a special microscope and stained preparations cannot be archived.
Comparison of IHC and FISH results among pathologist groups are presented in Table VI. Gene amplification could not be observed via FISH analysis in any of the samples that were evaluated as $2+$ and $3+$ by the pathologist in Group B. Of the samples evaluated as 2+ and $3+$ by thepathologist in Group A, $15.4 \%$ and $75 \%$ were FISHpositive, respectively. The rate of FISH-positivity was $44.4 \%$ in 2+ samples in Group C.

Table VI. Comparison of IHC and FISH results among pathologist groups.

\begin{tabular}{lccc}
\hline & & FISH (-) & FISH (+) \\
\cline { 3 - 4 } Pathologist & Previous IHC & $\mathbf{n}(\mathbf{\%})$ & $\mathbf{n}(\%)$ \\
\hline A & $\mathbf{0 - 1 +}$ & $\mathbf{1 4 ( 1 0 0 . 0 )}$ & $0(0.0)$ \\
& $\mathbf{2 +}$ & $66(84.6)$ & $\mathbf{1 2}(\mathbf{1 5 . 4 )}$ \\
& $\mathbf{3}+$ & $2(25.0)$ & $\mathbf{6 ( 7 5 . 0 )}$ \\
B & $\mathbf{2}+$ & $19(100.0)$ & $\mathbf{0 ( 0 . 0 )}$ \\
& $\mathbf{3}+$ & $1(100.0)$ & $\mathbf{0 ( 0 . 0 )}$ \\
C & $\mathbf{2 +}$ & $10(55.6)$ & $\mathbf{8 ( 4 4 . 4 )}$ \\
\hline
\end{tabular}

Whilst 0-1+ (HER2 negative) and 3+ (HER2 positive) IHC results show higher correlation with FISH, consistency of $2+$ results (HER2 equivocal) with FISH is contradictory (Yeh). FISH analysis is recommended for all samples that are found $2+$ and $3+$ by IHC (Kovács \& Stenman, 2010). Gene amplification could be demonstrated only in some of the samples that are found $2+$ by IHC (Yeh). Studies have reported that FISH positivity in IHC 2+ samples varies between $7 \%$ and 89\% (Ciampa et al., 2006; Rossi et al., 2006; Kuo et al., 2007; Sui et al., 2009; Goud et al., 2012; Zhang et al., 2012). Such diverse results might be due to the differences in the number of patients included in studies, centers' and/or pathologists' experience, and the test kits used.

Zhang et al. evaluated FISH results in 528 breast cancer samples with IHC $2+$. Of these samples, $65.5 \%$ of IHC $2+$ patients were negative for HER-2/neu amplification, 29.0\% were positive, and the remaining was equivocal. They emphasized that FISH analysis was necessary in the samples with IHC 2+. Ciampa et al. demonstrated that of the samples 
with IHC 3+, 52\% were FISH positive and $48 \%$ were FISH negative. However, samples with IHC 2+ were more discordant with FISH, of which, 93\% were FISH negative. FISH was found positive in two $(9.5 \%)$ of 21 samples that were IHC 0 1+. Goud et al. investigated HER2/neu status by IHC and FISH in 90 breast cancer tissues. Thirty samples yielded negative results with both methods. Of 28 samples with IHC $2+, 20$ were FISH positive and 3 were FISH negative, whereas 5 equivocal samples were found to be positive with repeated FISH testing. FISH was positive in 25 and negative in 7 of 32 samples with IHC $3+$. They also suggested that all samples with IHC $2+$ or higher should be analyzed also by FISH. Rossi et al. performed IHC and FISH in 81 samples and reported that IHC score and FISH evaluation showed a significant concordance (concordance coefficient 0.64). Gene amplification was not observed in any of the samples with IHC $0-1+$. Besides, gene amplification was detected in $20 \%$ of cases with IHC $2+$ and $77.78 \%$ of cases with IHC $3+$. In the study performed by Sui et al., with 50 samples, the total concordance was found to be $82.0 \%$ (Kappa coefficient $=0.640$, $\mathrm{p}<0.001)$. There was a high discordance in $30.0 \%$ of the patients with IHC $2+, 7.1 \%$ with IHC $3+$, and $19.2 \%$ with IHC $0-1+$. Kuo et al. performed a study with 54 samples and found that FISH was negative in all of IHC $1+$ samples, whereas FISH was positive in $53 \%$ of IHC 2+ samples and $83 \%$ of IHC $3+$ samples. Yaziji et al. (2004) evaluated 2,913 samples that underwent both IHC and FISH analyses and found positive predictive value of IHC $3+$ score to be $91.6 \%$ and negative predictive value of IHC $0-1+$ to be $97.2 \%$ when considered FISH as the standard test. The sensitivity of IHC was reported to be $92.6 \%$ when $2+$ and $3+$ scores were taken into account, whereas the specificity was reported to be $98.8 \%$ for IHC $3+$ scores. Based on the results of the study, they recommended verification by FISH analysis only for IHC $2+$ samples.

In brief, regarding the studies in the literature, consistency of IHC 0-1+ samples with FISH changes between $81 \%$ and $100 \%$ (Ciampa et al.; Goud et al.; Sui et al.; Kuo et al.). In the present study, all of the samples which were previously IHC $0-1+$ were again found to be $0-1+$ by reviewed IHC and FISH results were negative in $100 \%$ of these samples. In the literature, the FISH positivity in IHC 2+ samples is between 7\% and 89\% (Zhang et al.; Ciampa et al.; Goud et al.; Rossi et al.; Sui et al.; Kuo et al.). In the present study, the FISH positivity was $17 \%$ for previous IHC $2+$ samples and $23 \%$ for re-reviewed IHC $2+$ samples. Studies have been reported the consistency of IHC 3+ samples with FISH between 52\% and 94\% (Ciampa et al.; Goud et al.; Rossi et al.; Sui et al.; Kuo et al.). In the present study, consistency of IHC 3+ samples with FISH was 67\% for previous IHC results, whereas it was found to be $75 \%$ for re-reviewed IHC results. In our department, re-reviewed IHC results showed higher consistency with FISH.
It is known that IHC can give different results due to subjective interpretation, samples were re-reviewed in our clinic. All of the previously IHC $0-1+$ samples were again found $0-1+$ when re-reviewed in our clinic. When previously IHC $3+$ samples were re-reviewed in $88.9 \%$ was again $3+$. Of the previous IHC $2+$ samples, $25.2 \%$ were found $0-1+$ when re-reviewed, whereas $74.8 \%$ were found $2+$ again. The rate of consistency between previous and re-reviewed IHC results was determined to be $78.3 \%$. When IHC results were re-reviewed according to the pathologists that performed previous evaluation, $86(86 \%)$ of 100 samples evaluated by experienced pathologist were found to be consistent with the second evaluation. This consistency was $20 \%$ in the samples evaluated by inexperienced pathologist. When only $2+$ samples were taken into account, the rate of consistency was $82.1 \%$ and $21.1 \%$ for experienced and inexperienced pathologists, respectively. Hoang et al. (2000), investigated interobserver reproducibility in IHC testing and assigned 100 samples to 4 different pathologists. Umemura et al. (2008), investigated inconsistency between IHC and FISH results among different laboratories (7 institutional and 3 commercial laboratories in Japan, one laboratory in Germany) and the reasons for this inconsistency. Concordance among the laboratories was good for IHC $(\mathrm{k}=$ $0.713)$ and excellent for FISH $(\mathrm{k}=0.887)$. Discordance among the results was attributed to the evaluation process in $33.0 \%$ of the samples, staining procedures in $25.0 \%$, and both evaluation and staining procedures in $41.7 \%$.

In the present study, FISH was positive in $15.4 \%$ of the samples with IHC $2+$ and in $75 \%$ of the samples with ICH 3+ evaluated by the experienced pathologist. Gene amplification was not observed in any of the samples evaluated as $2+$ and $3+$ by the inexperienced pathologist. In the study conducted by Perez et al. (2006), 2,535 samples were examined at local and central laboratories and samples with inconsistent result were additionally examined at the reference laboratory. Among the patients evaluated as strongly HER 2 positive by local laboratories, a significant percentage of the patients were not confirmed by a central laboratory; $18.4 \%$ for IHC HercepTest and $11.9 \%$ for FISH. After re-evaluation of discordant samples in the reference laboratory, a high level of agreement between the central (Mayo Medical Laboratories) and reference laboratories was achieved as $94.3 \%$ for $\operatorname{IHC}(0,1$, and 2$)$ and $95.2 \%$ for FISH.

In conclusion, FISH test was negative in 131 (77.5\%) and positive in 38 (22.5\%) of 169 samples. When those with previous IHC $0-1+$ were re-reviewed, the results were found again $0-1+$ and none of them was FISH positive. Inconsistency between re-reviewed IHC and previous IHC results was $25 \%$ for those with $2+$ score and $11 \%$ for those 
with 3+ score. Consistency between IHC and FISH was 17\% and $67 \%$ for previous IHC $2+$ and $3+$, respectively, whereas it was $23 \%$ and $75 \%$ for re-reviewed IHC $2+$ and $3+$, respectively. Whilst $79 \%$ of the samples evaluated as $2+$ by the inexperienced pathologist were found to be $0-1+$ on the re-review, all of them were FISH negative.

Results of the present study supported the hypothesis that the consistency between IHC and FISH is higher for samples with $0-1+$ and $3+$ but variable for samples with $2+$. Since there may be differences due to subjective interpretation with IHC analysis, we recommend that samples with $2+$ should be re-reviewed by consulting with an experienced pathologist. Unnecessary requests for molecular test would be reduced by experienced pathologist by minimizing interpretation differences and by trained technicians and qualified techniques by minimizing evaluation errors.

SAGLICAN, Y. \& INCE, Ü. Estado del HER2/neu en especímenes con cáncer de mama: Comparación entre los métodos de inmunohistoquímica (IHC) y fluorescencia de hibridación in situ (FISH). Int. J. Morphol., 33(2):737-742, 2015.

RESUMEN: La amplificación o sobreexpresión de HER2 es un marcador predictivo de la respuesta al tratamiento en el cáncer de mama y es considerada como resultado de esta patología. El presente estudio tuvo como objetivo comparar los resultados de IHC y FISH para la determinación de HER2 y buscar diferencias de interpretación. Las muestras ( $\mathrm{n}=169)$, de las cuales 31 eran bloques de parafina, fueron enviadas desde centros externos y sometidas a análisis FISH para HER-2. Las muestras fueron revisadas en nuestro laboratorio con la prueba IHC. La prueba FISH resultó negativa en 131 casos $(77,5 \%)$ y positiva en $38(22,5 \%)$. Cuando se re-examinaron aquellos casos con resultados previos de IHC $0-1+$, se encontró que los resultados fueron iguales $(0-1+)$ y ninguno de ellos fue positivo para FISH. Se encontró inconsistencia entre los casos previos y las nuevas revisiones con IHC y fueron del $25 \%$ para aquellos casos con puntuación $2+$ y del $11 \%$ para aquellos con 3+ de puntuación. La consistencia entre IHC y FISH fue del 17\% y del $67 \%$ para casos previos analizados con IHC $2+$ y $3+$, respectivamente, mientras que fue de $23 \%$ y $75 \%$ para los reanalizados con IHC $2+$ y $3+$, respectivamente. Mientras que en el $79 \%$ de las muestras evaluadas con puntuación 2+ por patólogo inexperto resultaron ser $0-1+$ con la nueva revisión, todos estos casos fueron FISH negativos. De acuerdo con nuestros resultados, sugerimos que las muestras con puntuación 2+ de IHC deben ser re-evaluadas por un patólogo experimentado.

PALABRAS CLAVE: Cáncer de mama; HER2; Inmunocitoquímica; Técnica de FISH.

\section{REFERENCES}

Bravatà, V.; Cammarata, F. P.; Forte, G. I. \& Minafra, L. "Omics" of HER2-positive breast cancer. OMICS, 17(3):119-29, 2013.

Cayre, A.; Mishellany, F.; Lagarde, N. \& Penault-Llorca, F. Comparison of different commercial kits for HER2 testing in breast cancer: looking for the accurate cutoff for amplification. Breast Cancer Res., 9(5):R64, 2007.

Ciampa, A.; Xu, B.; Ayata, G.; Baiyee, D.; Wallace, J.; Wertheimer, M.; Edmiston, K. \& Khan, A. HER-2 status in breast cancer: correlation of gene amplification by FISH with immunohistochemistry expression using advanced cellular imaging system. Appl. Immunohistochem. Mol. Morphol., 14(2):132-7, 2006.

Ellis, C. M.; Dyson, M. J.; Stephenson, T. J. \& Maltby, E. L. HER2 amplification status in breast cancer: a comparison between immunohistochemical staining and fluorescence in situ hybridisation using manual and automated quantitative image analysis scoring techniques. J. Clin. Pathol., 58(7):710-4, 2005.

Goud, K. I.; Dayakar, S.; Vijayalaxmi, K.; Babu, S. J. \& Reddy, P. V. Evaluation of HER-2/neu status in breast cancer specimens using immunohistochemistry (IHC) \& fluorescence in-situ hybridization (FISH) assay. Indian J. Med. Res., 135:312-7, 2012.

Hoang, M. P.; Sahin, A. A.; Ordòñez, N. G. \& Sneige, N. HER-2/ neu gene amplification compared with HER-2/neu protein overexpression and interobserver reproducibility in invasive breast carcinoma. Am. J. Clin. Pathol., 113(6):852-9, 2000.

Jacot, W.; Fiche, M.; Zaman, K.; Wolfer, A. \& Lamy, P. J. The HER2 amplicon in breast cancer: Topoisomerase IIA and beyond. Biochim. Biophys. Acta, 1836(1):146-57, 2013.

Jelovac, D. \& Wolff, A. C. The adjuvant treatment of HER2-positive breast cancer. Curr. Treat. Options Oncol., 13(2):230-9, 2012.

Kovács, A. \& Stenman, G. HER2-testing in 538 consecutive breast cancer cases using FISH and immunohistochemistry. Pathol. Res. Pract., 206(1):39-42, 2010.

Kuo, S. J.; Wang, B. B.; Chang, C. S.; Chen, T. H.; Yeh, K. T.; Lee, D. J.; Yin, P. L. \& Chen, M. Comparison of immunohistochemical and fluorescence in situ hybridization assessment for HER-2/neu status in Taiwanese breast cancer patients. Taiwan J. Obstet. Gynecol., 46(2):146-51, 2007. 
Manion, E.; Hornick, J. L.; Lester, S. C. \& Brock, J. E. A comparison of equivocal immunohistochemical results with anti-HER2/ neu antibodies A0485 and SP3 with corresponding FISH results in routine clinical practice. Am. J. Clin. Pathol., 135(6):845$51,2011$.

Mukai, H. Treatment strategy for HER2-positive breast cancer. Int. J. Clin. Oncol., 15(4):335-40, 2010.

O'Grady, A.; Allen, D.; Happerfield, L.; Johnson, N.; Provenzano, E.; Pinder, S. E.; Tee, L.; Gu, M. \& Kay, E. W. An immunohistochemical and fluorescence in situ hybridizationbased comparison between the Oracle HER2 Bond Immunohistochemical System, Dako HercepTest, and Vysis PathVysion HER2 FISH using both commercially validated and modified ASCO/CAP and United Kingdom HER2 IHC scoring guidelines. Appl. Immunohistochem. Mol. Morphol., 18(6):489-93, 2010.

Perez, E. A.; Suman, V. J.; Davidson, N. E.; Martino, S.; Kaufman, P. A.; Lingle, W. L.; Flynn, P. J.; Ingle, J. N.; Visscher, D. \& Jenkins, R. B. HER2 testing by local, central, and reference laboratories in specimens from the North Central Cancer Treatment Group N9831 intergroup adjuvant trial. J. Clin. Oncol., 24(19):3032-8, 2006.

Ross, J. S. Breast cancer biomarkers and HER2 testing after 10 years of anti-HER2 therapy. Drug News Perspect., 22(2):93106, 2009.

Rossi, E.; Ubiali, A.; Cadei, M.; Balzarini, P.; Valagussa, E.; Lucini, L.; Alpi, F.; Galletti, A.; Fontana, L.; Tedoldi, C. \& Grigolato, P. HER-2/neu in breast cancer: a comparative study between histology, immunohistochemistry, and molecular technique (FISH). Appl. Immunohistochem. Mol. Morphol., 14(2):12731, 2006.

Sauter, G.; Lee, J.; Bartlett, J. M.; Slamon, D. J. \& Press, M. F. Guidelines for human epidermal growth factor receptor 2 testing: biologic and methodologic considerations. J. Clin. Oncol., 27(8):1323-33, 2009.

Sui, W.; Ou, M.; Chen, J.; Wan, Y.; Peng, H.; Qi, M.; Huang, H. \& Dai, Y. Comparison of immunohistochemistry (IHC) and fluorescence in situ hybridization (FISH) assessment for Her2 status in breast cancer. World J. Surg. Oncol., 7:83, 2009.

Umemura, S.; Osamura, R. Y.; Akiyama, F.; Honma, K.; Kurosumi, M.; Sasano, H.; Toyoshima, S.; Tsuda, H.; Rüschoff, J. \& Sakamoto, G. What causes discrepancies in HER2 testing for breast cancer? A Japanese ring study in conjunction with the global standard. Am. J. Clin. Pathol., 130(6):883-91, 2008.

Wolff, A. C.; Hammond, M. E.; Hicks, D. G.; Dowsett, M.; McShane, L. M.; Allison, K. H.; Allred, D. C.; Bartlett, J. M.; Bilous, M.; Fitzgibbons, P.; Hanna, W.; Jenkins, R. B.; Mangu, P. B.; Paik, S.; Perez, E. A.; Press, M. F.; Spears, P. A.; Vance, G. H.; Viale, G.; Hayes, D. F.; American Society of Clinical
Oncology \& College of American Pathologists. Recommendations for human epidermal growth factor receptor 2 testing in breast cancer: American Society of Clinical Oncology/College of American Pathologists clinical practice guideline update. J. Clin. Oncol.,31(31):3997-4013, 2013.

Yaziji, H.; Goldstein, L. C.; Barry, T. S.; Werling, R.; Hwang, H.; Ellis, G. K.; Gralow, J. R.; Livingston, R. B. \& Gown, A. M. HER-2 testing in breast cancer using parallel tissue-based methods. JAMA, 291(16):1972-7, 2004.

Yeh, I. T. Measuring HER-2 in breast cancer. Immunohistochemistry, FISH, or ELISA? Am. J. Clin. Pathol., 117 Suppl::S26-35, 2002.

Zhang, H.; Ren, G.; Wang, X.; Zhao, J.; Yao, H.; Bai, Y. \& Bo, W. HER-2 gene amplification by fluorescence in situ hybridization (FISH) compared with immunohistochemistry (IHC) in breast cancer: a study of 528 equivocal cases. Breast Cancer Res. Treat., 134(2):743-9, 2012.

Correspondence to:

Yesim Saglıcan

Department of Pathology

Acibadem University Faculty of Medicine

Maslak Hospital; Buyukdere cad No: 40, 34457

Istanbul

TURKEY

Email: ysaglican@hotmail.com

Received: 16-12-2014

Accepted: 01-04-2015 